\title{
Impact of Selectin Gene Polymorphisms on Rapid Progression to End-Stage Renal Disease in Patients with IgA Nephropathy
}

\author{
Yusuke Watanabe, Tsutomu Inoue, Hirokazu Okada, Shuhei Kotaki, \\ Yoshihiko Kanno, Tomohiro Kikuta and Hiromichi Suzuki
}

\begin{abstract}
Objective It is evident that leukocyte infiltration plays an important role in the pathogenesis of $\operatorname{IgA}$ nephropathy (IgAN). Selectin is one of the key adhesion molecules involved in leukocyte infiltration. Recent studies demonstrated a significant association between the selectin gene polymorphisms and susceptibility to IgAN. However, the impact of selectin gene polymorphisms on the progression to end-stage renal disease (ESRD) has not been studied.

Patients and Methods To evaluate the influence of the selectin gene polymorphisms on the progression of IgAN, we designed specific primers for PCR genotyping and analyzed the association of selectin gene polymorphisms with the declining rate in renal function to its ESRD.

Results A total of 61 hemodialysis patients were enrolled in the study. The mean age at renal biopsy was $33.0 \pm 13.3$ years old, and the mean age at the start of hemodialysis was $41.2 \pm 13.8$ years old. The mean interval between the time points of renal biopsy and the start of hemodialysis was $8.2 \pm 6.5$ years (ranging from 0 to 33 years). The interval was significantly longer in IgAN patients with a homoallele of C in C1402T, C 1402/C1402, of the E-selectin gene, or a homoallele of C in C712T, C712/C712, of the L-selectin gene compared to others. The haplotype, which is a combination of C1402/C1402 and C712/C712, is able to distinguish the group that is at least a better prognosis than the severest prognostic one.

Conclusion This study provides a possible association between the selectin gene polymorphisms and the rapid progression to ESRD in IgAN patients.
\end{abstract}

Key words: end-stage renal disease (ESRD), single nucleoside polymorphisms (SNPs), E-selectin, L-selectin

(DOI: 10.2169/internalmedicine.45.1641)

\section{Introduction}

Selectins are cell-cell adhesion molecules involved in the leukocyte-endothelial cell interaction that is required for extravasation of cells at the sites of tissue injury $(1,2)$. To date, three selectins have been characterized: E-selectin is expressed predominantly in cytokine-activated endothelial cells, L-selectin is expressed in circulating leukocytes, and P-selectin is expressed by platelets and activated endothelial cells $(1,2)$. Accumulation of leukocytes within the glomerulus and interstitium of the kidney is considered to be a key pathogenic mechanism in various types of glomerulonephritis including $\operatorname{IgA}$ nephropathy (IgAN) (1-3). IgAN is characterized by predominant $\operatorname{IgA}$ deposition in the glomerular mesangial area, and is now recognized as the most common form of chronic glomerulonephritis throughout the world (4).

The course of IgAN was first considered to be benign, but it has now become apparent that approximately $40 \%$ of these patients gradually lose their renal function and eventually progress to end-stage renal disease (ESRD) within 20 years $(4,5)$. Based on these studies, patients can be roughly classified into three groups in view of their clinical course. 
The first group maintains renal function for more than 20 years, the second exhibits a progressive course and results in ESRD within 20 years (poor prognosis), and the third progresses more rapidly than the second, and dialysis is necessary within 5 years (very poor prognosis). Several clinical factors constitute a poor prognosis for patients with IgAN. These factors include impaired renal function at the time when renal biopsy is performed, the presence of proteinuria, hypertension, and histological renal damage including tubulointerstitial alterations (4). To predict whether a patient has a 'poor'/"very poor' prognosis is not distressing to most clinicians. In contrast, it is difficult to distinguish between a 'poor' and 'very poor' prognosis except for cases that appear to be crescentic or necrotizing glomerular nephritis, which indicates rapidly progressive glomerulonephritis.

Although the exact mechanisms governing the fate of renal function in $\operatorname{IgAN}$ are unclear, genetic factors are presumed to participate in its development and progression (46). In particular, the correlation between the development of IgAN and single-nucleotide polymorphisms (SNPs) in genes that encode nephritis-related molecules have become the focus of attention $(6,7)$. Takei et al performed a case-control association study of IgAN that was based on linkage disequilibrium among SNPs in the selectin gene cluster on chromosome 1q 24-25. They found two SNPs in the Eselectin gene and six SNPs in the L-selectin gene that were significantly associated with the development of $\operatorname{IgAN}(8)$. In these SNPs, the E-selectin gene C1402T and L-selectin gene $\mathrm{C} 712 \mathrm{~T}$ code SNPs resulting in amino acid substitutions from His to Tyr and from Pro to Ser, respectively. The Lselectin gene (A-642 G) which is located on the $5^{\prime}$ flanking region is thought to affect promoter activity of the L-selectin gene (8). In addition, it has also been demonstrated recently that one of the E-selectin polymorphisms (A561C) alters leukocyte-endothelial interactions and is associated with an increased risk of myocardial infarction (9).

In the present study, the effect of these selectin gene polymorphisms on the progression of IgAN to ESRD was retrospectively evaluated by analyzing the association of the SNPs in the E-selectin gene (A561C, C1402T) and those of the L-selectin gene (A-642 G, C712T) with a declining rate of renal function to ESRD in patients with renal biopsyproven $\operatorname{Ig} \mathrm{AN}$.

For editorial comment, see p 939.

DOI: 10.2169/internal medicine.45.0154

\section{Patients and Methods}

\section{Patients}

The protocol of the present study was approved by the ethics committee of the institution involved. Hemodialysis patients were surveyed at Saitama Medical College Hospitals (Saitama, Japan) and our affiliated hemodialysis clinics. All of the patients who fulfilled the following criteria were
Table 1. Primers Constructed for the Determination of Polymorphisms

(1) SELE (C1402T) polymorphisms

Forward (C1402) - TGAGGAGGGATTTGAATTAC

Forward (T1402) -TGAGGAGGGATTTGAATTAT

Reverse - ACAACCACCATCAATCAATGC

(2) SELE (A561C) polymorphisms

Forward - ATGGCACTCTGTAGGACTGCT

Reverse - GTCTCAGCTCACGATCACCAT

(3)SELL (A-642G) polymorphisms

Forward (A-642) - GCCACTTAACAAGGACGTCCA

Forward (G-642) - GCCACTTAACAAGGACGTCCG

Reverse - AGTAATGTGACTAGATTCTC

(4)SELL (C712T) polymorphisms

Forward (C712) - TACCATGGACTGTACTCACC

Forward (T712) - TACCATGGACTGTACTCACT

Reverse - TGCAATGGCAATGAGAAAAA

recruited: 1) Informed consent for genetic study was obtained. 2) Patients who had been diagnosed as having IgAN by renal biopsy. 3) Patients who had progressed to ESRD without any complication other than IgAN.

According to our renal biopsy inclusion criteria, we routinely performed renal biopsy in patients with a serum creatinine level of less than $1.3 \mathrm{mg} / \mathrm{dl}$ and proteinuria of more than $0.5 \mathrm{~g} /$ day. The criteria for starting hemodialysis were based on the agreement of Japanese Ministry of Health, Labor and Welfare. In brief, 1) renal dysfunction (serum creatinine over $8 \mathrm{mg} / \mathrm{dl}$ and creatinine clearance under $10 \mathrm{ml} /$ min). 2) clinical symptoms caused by fluid retention, electrolyte imbalance and uremia. 3) disability of daily life caused by uremia was evaluated and each parameter was scored and the patients beyond the cut-off were started on hemodialysis.

All enrolled patients were considered to have a poor prognosis because they eventually received hemodialysis. They are classified as 'poor' or 'very poor' based on the interval between the time points of renal biopsy and start of hemodialysis; the border is 5 years.

\section{Extraction of genomic DNA and genotyping}

Genomic DNA was prepared from peripheral blood leukocytes of each patient using QIAamp DNA Blood Midi Kit (Qiagen, Hilden, Germany). To determine the selectin gene SNPs, specific primers were constructed (Table 1). PCR was carried out in $50 \mu$ final volume containing $100 \mathrm{ng}$ genomic DNA, $1 \mu \mathrm{M}$ of each primer, $0.5 \mathrm{mM}$ of each dNTP, $50 \mathrm{mM}$ $\mathrm{KCl}, 10 \mathrm{mM}$ Tris- $\mathrm{HCl}, \mathrm{pH} 8.4,0.1 \mathrm{mg} / \mathrm{ml}$ gelatin, $1.5 \mathrm{mM}$ $\mathrm{MgCl}_{2}, 15 \mathrm{ml} / \mathrm{L}$ formamide, 1 unit of Taq DNA polymerase. Thermal cycling was done in a PCR Thermal Cycler 480 (Takara Shuzo, Shiga, Japan) with the following cycling parameter for 25 cycles: denaturation at $95^{\circ} \mathrm{C}$ for 30 seconds, annealing at $62^{\circ} \mathrm{C}$ for 30 seconds, and extension at $72^{\circ} \mathrm{C}$ for 
A

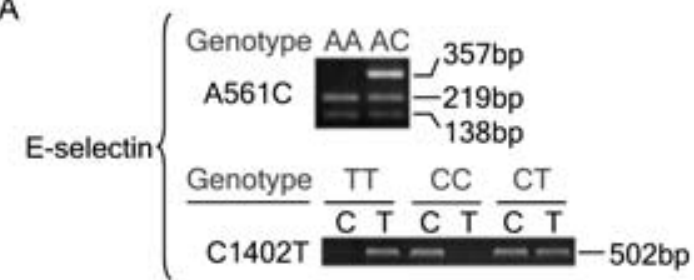

B

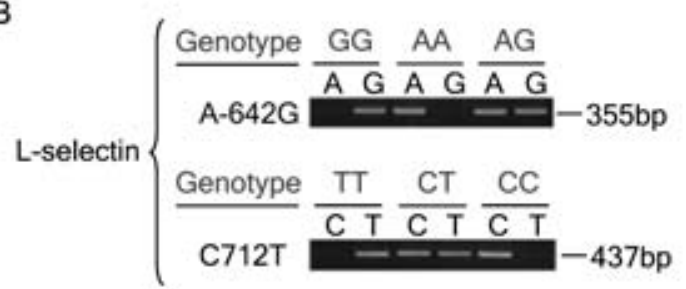

Figure 1. Representative pictures for agarose gel-separated PCR products indicating genotypes. A561C and C1402T are SNPs in E-selectin gene; A-642G and C712T are SNPs in Lselectin gene. bp: base pairs.

1 minute. DNA fragments amplified by PCR were separated by $1 \%$ agarose gel electrophoresis. After electrophoresis, the gel was stained with ethidium bromide and visualized by UV transillumination. Genotyping of each polymorphism was determined by the presence of appropriate size bands of DNA fragments. (1) E-selectin (A561C) polymorphisms (Fig. 1A): the DNA fragment amplified by PCR was digested with 20 unit Pst I (Takara Shuzo, Shiga, Japan) for 1 hour at $37^{\circ} \mathrm{C}$ and separated on $1 \%$ agarose gel by electrophoresis. The A allele was suggested by the presence of 219 base pairs (bp) and 138 bp bands, whereas the $\mathrm{C}$ allele is defined by the loss of Pst I site, yielding an undigested 357 bp band. (2) E-selectin (C1402T) polymorphisms (Fig. 1A): the presence of $502 \mathrm{bp}$ band when using forward (C1402) primer indicates $\mathrm{C} 1402$ allele, and the presence of $502 \mathrm{bp}$ band when using forward (T1402) primer indicates T1402 allele. (3) L-selectin (A-642 G) polymorphisms (Fig. 1B): the presence of a 355 bp band when using forward (A-642) primer indicates A-642 allele, and the presence of a $355 \mathrm{bp}$ band when using forward (G-642) primer indicates G-642 allele. (4) L-selectin (C712T) polymorphisms (Fig. 1B): the presence of a $437 \mathrm{bp}$ band when using forward (C712) primer indicates $\mathrm{C} 712$ allele, and the presence of a $437 \mathrm{bp}$ band when using forward (T712) primer indicates T712 allele. Not all the PCR products, but a couple of them were examined by a direct sequence technique in order to confirm the validity of the result obtained by PCR.

\section{Statistical analysis}

The clinical parameters were expressed as mean \pm standard deviation. StatView 5.0 J software (SAS Institute Inc, Cary, North Carolina, USA) was used for statistical analysis. Using the same software, $\chi^{2}$ tests were performed to compare categorical data. A P value of less than 0.05 was considered statistically significant. A relationship between genotypic
Table 2. Genotype Distribution and Allele Frequency of the E- and L-selectin Gene

\begin{tabular}{|c|c|c|c|c|c|c|c|c|}
\hline \multirow{3}{*}{$\begin{array}{l}\text { SNPs } \\
\text { Allele }\end{array}$} & \multicolumn{4}{|c|}{ E-selectin } & \multicolumn{4}{|c|}{ L-selectin } \\
\hline & \multicolumn{2}{|c|}{ A561C } & \multicolumn{2}{|c|}{ C1402T } & \multicolumn{2}{|c|}{$A-642 G$} & \multicolumn{2}{|c|}{ C712T } \\
\hline & A & 0.926 & C & 0.754 & A & 0.648 & C & 0.746 \\
\hline & C & 0.074 & $\mathrm{~T}$ & 0.246 & $\mathrm{G}$ & 0.352 & $\mathrm{~T}$ & 0.254 \\
\hline \multirow[t]{3}{*}{ Genotype } & $A A$ & 0.852 & $\mathrm{CC}$ & 0.541 & $A A$ & 0.590 & $\mathrm{CC}$ & 0.606 \\
\hline & $A C$ & 0.148 & CT & 0.426 & $A G$ & 0.115 & CT & 0.279 \\
\hline & $\mathrm{CC}$ & 0.000 & TT & 0.033 & GG & 0.295 & $\mathrm{TT}$ & 0.115 \\
\hline
\end{tabular}

Table 3. Statistically Significant Differences in Frequency of SNPs Among Different Prognostic Categories

\section{A}

\begin{tabular}{|c|c|c|c|c|c|c|c|c|c|c|c|}
\hline \multirow{2}{*}{$\begin{array}{c}\text { SNPs } \\
\text { Genotype }\end{array}$} & \multicolumn{2}{|c|}{ A561C } & \multicolumn{3}{|c|}{ C1402T } & \multicolumn{3}{|c|}{$\mathrm{A}-642 \mathrm{G}$} & \multicolumn{3}{|c|}{$\mathrm{C} 712 \mathrm{~T}$} \\
\hline & AA & $A C$ & $\mathrm{CC}$ & CT & TT & AA & $A G$ & GG & $\mathrm{CC}$ & CT & TT \\
\hline Poor & 29 & 3 & 22 & 9 & 1 & 23 & 3 & 6 & 24 & 5 & 3 \\
\hline Very poor & 23 & 6 & 11 & 17 & 1 & 13 & 4 & 12 & 13 & 12 & 4 \\
\hline & \multicolumn{2}{|c|}{$\begin{aligned} \chi^{2} & =1.55 \\
P & =0.21\end{aligned}$} & & \multicolumn{2}{|c|}{$\begin{aligned} \chi^{2} & =6.01 \\
P & <0.05\end{aligned}$} & \multicolumn{3}{|c|}{$\begin{array}{l}\chi^{2}=4.79 \\
P=0.09\end{array}$} & \multicolumn{3}{|c|}{$\begin{aligned} \chi^{2} & =6.16 \\
P & <0.05\end{aligned}$} \\
\hline
\end{tabular}

B

\begin{tabular}{ccc}
\hline \multirow{2}{*}{ SNPs } & \multicolumn{2}{c}{ C1402T / C712T } \\
\cline { 2 - 3 } Haplotype & C1402/C1402 & \\
& $\&$ C712/C712 & Others \\
\hline Poor & 20 & 12 \\
Very poor & 8 & 21 \\
\hline & & $\chi^{2}=7.47$ \\
& & $P=0.006$ \\
\hline
\end{tabular}

frequency and gene frequency perfectly matched the expectation under Hardy-Weinberg principal.

\section{Results}

A total of 61 cases, comprising 38 male and 23 female patients, was enrolled. The mean age at renal biopsy was $33.0 \pm 13.3$ years old, and the mean age at the start of hemodialysis was $41 \pm 3.8$ years old. The mean interval between renal biopsy and start of hemodialysis was $8.2 \pm 6.5$ years (ranging from 0 to 33 years). Table 2 shows genotype distribution and allele frequencies of E-selectin and L-selectin gene polymorphisms in these patients. In previous studies from Takei et al (8), there was not a large difference in the allele frequencies with respect to E-selectin C1402T, Lselectin A $642 \mathrm{G}$, and L-selectin C712T in IgAN patients. As shown in Table 3, there was a statistically significant relationship between the prognostic categories and the genotype of C1402T and C712T. More than the 'poor' prognosis cases had homoallele of $\mathrm{C}$ in $\mathrm{C} 1402 \mathrm{~T}$ of E-selectin than did the 'very poor' cases $\left(22\right.$ versus $\left.11, \chi^{2}=6.01, \mathrm{P}<0.05\right)$. Homoallele of $\mathrm{C}$ in C712T for L-selectin showed a significantly higher frequency in the 'poor' prognostic cases than in the 'very poor' prognostic cases ( 24 versus $13, \chi^{2}=6.16, \mathrm{P}$ $<0.05$ ). Moreover, a combination of both homoalleles, $\mathrm{C}$ 
1402/C1402 and C712/C712, anticipate at least a better prognosis than the severest one (Table $3 \mathrm{~B}$ ).

\section{Discussion}

In the present study, we demonstrated the association between the selectin gene polymorphisms, C1402T and C712T SNPs, and the progression to ESRD in IgAN patients. Although the enrolled patients are a relatively poor prognostic group in $\operatorname{IgAN}$, the interval between renal biopsy and start of hemodialysis was significantly longer in $\operatorname{IgAN}$ patients with $\mathrm{C} 1402 / \mathrm{C} 1402$ of the E-selectin gene or C712/C712 of the L-selectin gene when compared to other genotypes.

Infiltration of leukocytes into glomerular and interstitial regions of the kidney is accepted as one of the key pathogenic mechanisms in glomerulonephritis $(1,2)$. This involves a series of specific interactions between adhesion molecules expressed on circulating leukocytes and their ligands on endothelial and other cell types. To date, three main groups of adhesion molecules known to be involved in these interactions are the selectins, the integrins, and certain members of immunoglobulin super family $(1,2)$. It was reported that there is a marked increase in E-selectin and Pselectin expression on the extraglomerular vascular endothelium, with prominent interstitial infiltrates, in some biopsy samples from patients with $\operatorname{IgAN}$, and a large number of Lselectin-positive cells were present within glomerular and interstitial infiltrates in the affected kidney (2). Lai et al demonstrated an apparent increase in serum levels of E-selectin that was associated with an increased histopathological grade (11), when patients with IgAN were stratified according to the severity of their glomerular and interstitial lesions. Moreover, an increased expression of E-selectin has been observed on renal interstitium that contains lymphocytes and macrophages, along with an increase in the circulating level of soluble L-selectin (11). In addition to these results, we have demonstrated that SNPs of these selectin genes associate with not only development, but also progression to ESRD of IgAN. The precise mechanism is unknown, however, there is a possibility that these selectin gene polymorphisms may affect the quality and quantity of selectin protein and alter the interaction between the endothelium and leukocytes in the kidney. One of the aims of genetic study is to provide knowledge about the prognosis of a given disease. IgAN shows large inter-individual variations in the rate of progression to ESRD. The finding that the carriage of these selectin polymorphisms may predispose patients to a very poor outcome supports the prevalence of intensive ther- apy on such patients with IgAN. Our study suggests that the genotype of the T1402C polymorphism of the E-selectin gene, and the C712T polymorphisms of the L-selectin gene can lead to a more accurate estimation of the prognosis of IgAN patients. Furthermore, modification of the function of selectin can become a target of new therapy.

We have documented the impact of selectin gene polymorphisms on susceptibility and also progression of IgAN. But we should recognize the limitation of this study. We analyzed SNPs of several genes as a progressive factor, but other factors, such as an elevated serum creatinine level at presentation, severe proteinuria at presentation and/or during follow-up, severe histological damage at renal biopsy, arterial hypertension at presentation, older age at presentation, and male sex, have been recognized as a valuable predictors of progression (12). We analyzed the patients' clinical parameters retrospectively; we could not collect enough information for multivariate Cox proportional hazards regression analysis. Also, the number of patients in this study is relatively small so we could not rule out potential false-negative results that we concluded as statistically not significant. In addition, we chose hemodialysis patients with renal biopsy proven $\operatorname{IgAN}$ as the parent population, so there was genetic bias that this may not have yielded the correct result. Moreover, according to our results, homoalleles C1402/C1402 and $\mathrm{C} 712 / \mathrm{C} 712$ anticipate the prognosis; however there seems not to be significant linkage disequilibrium between $\mathrm{C} 1402 \mathrm{~T}$ and $\mathrm{C} 712 \mathrm{~T}$. In these respects, further investigation with a long-term prospective observation of a large number of cases is necessary for confirmation of the present findings. We also examined SNPs in genes encoding molecules that were thought to be related to the pathogenesis of $\operatorname{IgAN}$, e.g. angiotensin-converting enzyme insertion/deletion (1315), angiotensinogen (AGT) M235T $(16,17)$, AGT A-20C (18), transforming growth factor- $\beta_{1}$ C-509T (19), C-C chemokine receptor 5 G59029A (20), and monocyte chemoattractant protein-1 G-2518A (20). But we did not find any significant association between any of these SNPs and the interval from renal biopsy and start of hemodialysis of the same patients enrolled in this study (data not shown).

In conclusion, this work provides a possible association between the loss of homoalleles of C1402/C1402 or C712/C 712 of the E-/L-selectin genes, and phenotype of rapid progression to ESRD in $\operatorname{IgAN}$ patients.

The authors wish to thank M. Otobe for her excellent technical assistance.

\section{References}

1. Adler S, Brady HR. Cell adhesion molecules and the glomerulopathies. Am J Med 107: 371-386, 1999.

2. Roy-Chaudhury P, Wu B, King G, et al. Adhesion molecule interactions in human glomerulonephritis: importance of the tubulointerstitium. Kidney Int 49: 127-134, 1996.
3. Kanno Y, Suzuki H, Okada H, Nakazato Y, Saruta T. Retroviral infection in peripheral mononuclear cells in patients with $\operatorname{IgA}$ nephropathy. Clin Nephrol 47: 211-216, 1997.

4. Donadio JV, Grande JP. IgA nephropathy. N Engl J Med 347: 738-748, 2002. 
5. Nagasawa R, Matsumura $O$, Maruyama N, Mitarai T, Isoda K. Tcell receptor beta-chain gene polymorphism and the prognosis of IgA nephropathy in Japanese patients. Nephron 70: 502-503, 1995.

6. Hsu SI, Ramirez SB, Winn MP, Bonventre JV, Owen WF. Evidence for genetic factors in the development and progression of IgA nephropathy. Kidney Int 57: 1818-1835, 2000.

7. Mustonen J, Syrjanen J, Rantala I, Pasternack A. Clinical course and treatment of IgA nephropathy. J Nephrol 14: 440-446, 2001.

8. Takei T, Iida A, Nitta $K$, et al. Association between singlenucleotide polymorphisms in selectin genes and immunoglobulin A nephropathy. Am J Hum Genet 70: 781-786, 2002.

9. Yoshida M, Takano Y, Sasaoka T, Izumi T, Kimura A. E-selectin polymorphism associated with myocardial infarction causes enhanced leukocyte-endothelial interactions under flow conditions. Aterioscler Thromb Vasc Biol 23: 783-788, 2003.

10. Okada H, Suzuki H, Konishi K, Sakaguchi H, Saruta T. Histological alterations in renal specimens as indicators of prognosis of IgA nephropathy. Clin Nephrol 37: 235-238, 1992.

11. Lai KN, Wong KC, Li PK, et al. Circulating leukocyte-endothelial adhesion molecules in IgA nephropathy. Nephron 68: 294-300, 1994.

12. D'Amico G. Natural history of idiopathic IgA nephropathy: role of clinical and histological prognostic factors. Am J Kidney Dis 36: 227-237, 2000.

13. Baudin B. New aspects on angiotensin-converting enzyme: from gene to disease. Clin Chem Lab Med 40: 256-265, 2002.

14. Hunley TE, Julian BA, Phillips JA 3rd, et al. Angiotensin converting enzyme gene polymorphism: potential silencer motif and impact on progression in IgA nephropathy. Kidney Int 49: 571-577, 1996.

15. Yoshida H, Mitarai T, Kawamura T, et al. Role of the deletion of polymorphism of the angiotensin converting enzyme gene in the progression and therapeutic responsiveness of IgA nephropathy. J Clin Invest 96: 2162-2169, 1995.

16. Narita I, Goto S, Saito N, et al. Interaction between ACE and ADD1 gene polymorphisms in the progression of IgA nephropathy in Japanese patients. Hypertension 42: 304-309, 2003.

17. Pei Y, Scholey J, Thai K, Suzuki M, Cattran D. Association of angiotensinogen gene T235 variant with progression of immunoglobin A nephropathy in Caucasian patients. J Clin Invest 100: 814820, 1997.

18. Goto S, Narita I, Saito N, et al. A (-20) C polymorphism of the angiotensinogen gene and progression of $\operatorname{IgA}$ nephropathy. Kidney Int 62: 2002.

19. Pociot F, Hansen PM, Karlsen AE, Langdahl BL, Johannesen J, Nerup J. TGF-b1 gene mutations in insulin-dependent diabetes mellitus and diabetic nephropathy. J Am Soc Nephrol 9: 23022307, 1998.

20. Nakajima K, Tanaka Y, Nomiyama T, et al. Chemokine receptor genotype is associated with diabetic nephropathy in Japanese with type 2 diabetes. Diabetes 51: 238-242, 2002.

(C) 2006 The Japanese Society of Internal Medicine

http://www.naika.or.jp/imindex.html 